九州大学学術情報リポジトリ

Kyushu University Institutional Repository

\title{
A PRACTICAL ESTIMATION METHOD OF THE SKIN PLATE DISTORTION CAUSED BY FILLET WELD
}

Gotoh, Koj i

Department of Marine Systems Engineering Kyushu University

Toyosada, Masahiro

Department of Marine Systems Engineering Kyushu University

http://hdl. handle. net/2324/4752584

出版情報: Proceedings of ASME 2002 21st International Conference on Offshore Mechanics and Arctic Engineering, pp. 113-119, 2009-02-24. The American Society of Mechanical Engineers : ASME

バージョン：

権利関係: Copyright（c）2002 by ASME 
OMAE'02-28181

\title{
A PRACTICAL ESTIMATION METHOD OF THE SKIN PLATE DISTORTION CAUSED BY FILLET WELD
}

\author{
Koji GOTOH* and Masahiro TOYOSADA \\ Department of Marine Systems Engineering \\ Kyushu University \\ Hakozaki 6-10-1,Higashi-ku,Fukuoka,812-8581 \\ JAPAN \\ Email: gotoh@nams.kyushu-u.ac.jp
}

\section{ABSTRACT}

Development of a useful estimation method of the welding deformation about welded built-up structures is developed in this paper. Improvement of matching accuracy of each hull block element is essential to introduce the economical automatic welding machines in an assembly stage. Precise estimation method of the welding deformation is also necessary to achieve the aim.

Equivalent inherent strain method is highlighted as a convenient estimation method about welding deformation in large welded built-up structures. Inherent strain can be seen as the deformation source generated by welding and derives from the thermal cycles under welding processes. This deformation source can be given if the amount of welding heat input is known. The deformation can be calculated by elastic finite element analysis. Shell element is applied to simplify the mesh idealization. However, this method did not give a good estimation result in case that out-of-plane deformation such as a skin plate distortion occurs.

Improvement of equivalent inherent strain method to advance the accuracy of estimation about the skin plate distortion caused by fillet weld is performed in this paper. Beam element, which expresses the fillet weld bead and has inherent strain along the bead to generate tendon force, is incorporated with former equivalent inherent strain method. The skin plate distortion measured are compared with the calculated one by applying the proposed method. As a result, the validity of the improvement is confirmed.

\footnotetext{
*Address all correspondence to this author.
}

\section{INTRODUCTION}

The assembly accuracy of each hull block element must be improved in order to apply a single automated welding machines to the block built-up stages. Welding deformation, which occurs during the hull block built-up processes by welding, is one of the main causes to become worse the matching accuracy of builtup blocks and to prevent from introducing the single automatic welding machine into the stages.

Many research projects concerning this problem have been performed and some practical and precise methods to estimate the welding deformation have proposed. Equivalent inherent strain method (Murakawa et al., 1998) is one of the convenient estimation methods about welding deformation in large welded built-up structures. Inherent strain, which can be considered as the deformation source of welding deformation and derives from thermal cycles caused by the welding, is applied to this method. This source can be given if the amount of welding heat input is known. The deformation can be calculated by elastic finite element analysis idealized by shell type element to simplify the modeling. However, this method could not give a good estimation result in case of generating out-of-plane deformation such as a skin plate distortion.

In this paper, improvement of equivalent inherent strain method about the estimation of skin plate distortion generated by fillet weld is performed. In order to discribe the deformation source precisely, beam element to express the fillet weld bead is incorporated with former equivalent inherent strain method. 


\section{CALCULATION METHOD FOR WELDING DEFORMA- TION}

Improvement of equivalent inherent strain method based on elastic finite element analysis is the main target of this research. Outline of the method and the affection of mesh size to the calculation result are stated in the first three subsections. Incorporating the beam element with former equivalent inherent strain method to express the fillet weld bead is explained following subsection.

\section{Outline of the Equivalent Inherent Strain Method}

Welding deformation can be described by the methodology of inherent strain derived from weld thermal cycles and plastic constraint at high temperature. Inherent deformation can be defined by the integration of inherent strain and classified into transverse shrinkage, angular distortion and longitudinal shrinkage. Transverse shrinkage and angular distortion are evaluated as an amount of deformation, i.e. length of shrinkage and change of angle. Longitudinal shrinkage is converted into Tendon Force to investigate this as a matter of convenience. These three deformations are normally measured in the experiments concerning welding deformation and expressed as a function of heat input.

In the estimation of the welding deformation in large welded built-up structures, inputting the detailed inherent strain distributions are unnecessary. Only the equivalent inherent strain, which is converted from the three component of inherent deformation and enable to generate the same deformation, should be inputted in the elements neighboring the weld lines. This method is so called "Equivalent Inherent Strain Method". Flow of the method to calculate welding deformation is as follows.

1. Calculation of the inherent deformations (transverse shrinkage, angular distortion and longitudinal shrinkage) from information of the heat input in each welding.

2. Conversion from the inherent deformations to the equivalent inherent strains.

3. Input the inherent strains into finite elements neighboring weld lines.

4. Elastic finite element analysis.

\section{Calculation of Equivalent Inherent Strain}

Transverse shrinkage and angular distortion can be expressed as a function of heat input parameter $Q_{n} / h^{2}$ (Terasaki et al., 1976), where $Q_{n}$ is the net heat input into plate per unit length and $h$ is plate thickness. On the other hand, tendon force is expressed as a function of the net heat input per unit length (White, 1980). These formulae are listed as follows.

$$
\begin{aligned}
S & =B_{1}(L) S_{0} \\
\theta & =B_{2}(L) \theta_{0} \\
F_{T} & =0.2 Q_{n}
\end{aligned}
$$

where ,

$$
\begin{aligned}
& S_{0}=\left\{\begin{array}{l}
1.16 \times 10^{-3} Q_{n} / h\left(Q^{*} \leq 6.27\right) \\
h\left\{1.44 \times 10^{-4}\left[\left(Q^{*}\right)^{2}-Q^{*}\right]\right. \\
\left.+2.5 \times 10^{-3}\right\}\left(6.27<Q^{*} \leq 20\right) \\
2.85 \times 10^{-3} Q_{n} / h\left(Q^{*}<20\right)
\end{array}\right. \\
& B_{1}(L)=\left[4 \tan ^{-1}(L / 200)+(L / 100)\right. \\
& \left.\times \log \left(1+40000 / L^{2}\right)\right] / 3.74 \\
& \theta_{0}=\left\{\begin{array}{l}
1.44 \times 10^{-3} Q^{*}\left(Q^{*} \leq 6.27\right) \\
1.06 \times 10^{-1} Q^{*} /\left\{\left(Q^{*}-6.16\right)^{2}\right. \\
+73.6\}\left(6.27<Q^{*}\right)
\end{array}\right. \\
& B_{2}(L)=\left[8 \tan ^{-1}(L / 120)+(1+v)(L / 60)\right. \\
& \left.\times \log \left(1+14400 / L^{2}\right)\right] / 8.82 \\
& S \quad \text { Transverse shrinkage [mm] } \\
& \theta \quad \text { Angular distortion [rad] } \\
& F_{T} \quad \text { Tendon force }[\mathrm{kN}] \\
& L \quad \text { Length of weld line [mm] } \\
& v \text { Poisson's ratio } \\
& Q_{n} \quad \text { Net heat input per unit length [J/mm] } \\
& h \quad \text { Plate thickness [mm] } \\
& Q^{*}=Q_{n} / h^{2}\left[\mathrm{~J} / \mathrm{mm}^{3}\right]
\end{aligned}
$$

These formulae can be applied to standard mild steels and high strength steels (including TMCP steels) commonly used in ships.

Although many inherent strain distiributions, which enable to express the same welding deformation, can be given, two types of equivalent inherent strain distribution are used in this method for a convenience of applying to the finite element analysis using shell type element. One is uniform along thickness direction (membrane component: $\varepsilon^{m}$ ). The other is linear along thickness direction (bending component: $\varepsilon^{b}$ ). These equivalent inherent strains corresponding to the three inherent deformations can be calculated. Component corresponding to longitudinal shrinkage $\left(\varepsilon_{x}^{m i}\right)$, transverse shrinkage $\left(\varepsilon_{y}^{m i}\right)$ and angular distortion $\left(\varepsilon_{y}^{b i}\right)$ are shown in equations (4) to (6) respectively.

$$
\begin{aligned}
\varepsilon_{x}^{m i} & =c_{i} F_{T} /\left(E h b_{i}\right) \\
\varepsilon_{y}^{m i} & =c_{i} S / b_{i} \\
\varepsilon_{y}^{b i} & =-z \kappa
\end{aligned}
$$

where,

$$
\begin{array}{ll}
E & \text { Young's modulus [MPa] } \\
b_{i} & \text { Both sides of the element width } \\
& \text { neighboring weld line (i=1,2) } \\
c_{1} & =b_{1} /\left(b_{1}+b_{2}\right) \\
c_{2} & =b_{2} /\left(b_{1}+b_{2}\right) \\
z & \text { Coordinate for plate thickness direction } \\
\kappa & \text { Curvature }\left(=\theta / b_{i}\right) .
\end{array}
$$




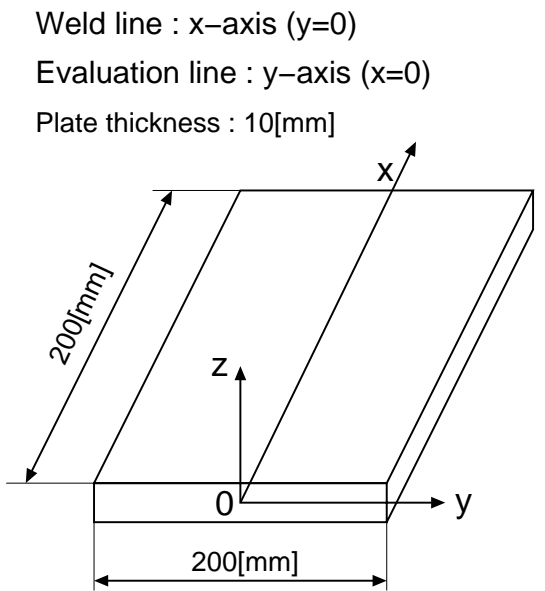

Figure 1. CALCULATION MODEL

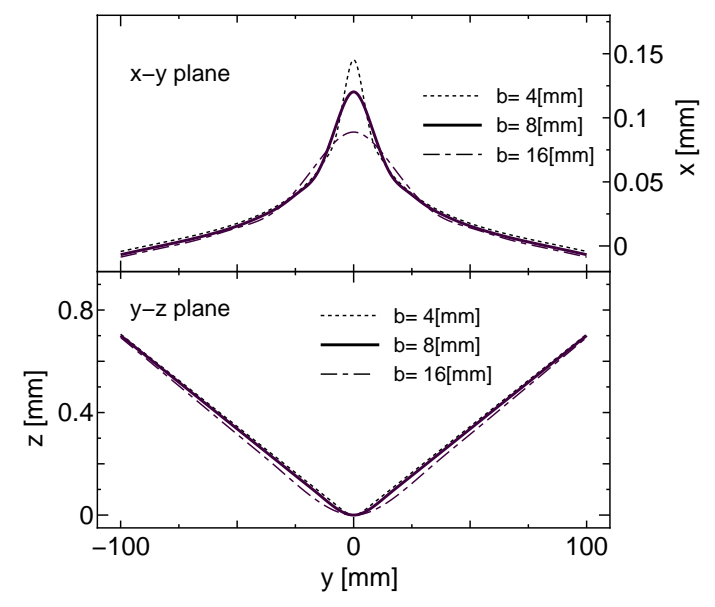

Figure 2. DEFORMATION OF THE PALNE on $x=0$

\section{Effect of The Element Width Inputting Equivalent Inher- ent Strain}

It is recommended that the element width inputting equivalent inherent strain corresponds to the actual existence region of the inherent strain generated by welding. This region is equal that the peak temperature during the welding exceeds $\sigma_{0} / E \alpha$, where $\sigma_{0}$ is yield stress and $\alpha$ is the coefficient of thermal expansion of material (Murakawa et al., 1996). The recommended element width can be approximate

$$
b^{2} \approx 0.117(\alpha / c \rho)\left(E / \sigma_{0}\right) Q_{n}
$$

where line heat source is supposed in deriving equation.

In order to investigate the effect of the element width to the result, series analyses varying the width are performed. Figure 1 is the model of analyses. Bead on plate welding along the $\mathrm{x}$-axis in figure 1 are supposed. Net heat input per unit weld length is fixed to $500 \mathrm{~J} / \mathrm{mm}$.

Three types of the element width neighboring weld line are tried. Each width are 4.0, 8.0, $16.0 \mathrm{~mm}$ respectively, because an appropriate element width in the example problem is $7.8 \mathrm{~mm}$ from equation (7). Each element shape is approached to square as long as possible.

Figure 2 shows the deformation on $x=0$ estimated by the equivalent inherent strain method. Upper side and lower side are the shape of $x-y$ plane and $y-z$ plane respectively. As a result of figure 2 , the element width neighboring weld line affects the insignificant calculation result except the neighbor of the edge of weld line.

It is concluded that the element width inputting equivalent inherent strain can be permitted about twice as long as one by equation (7).

\section{Modeling of Fillet Weld Bead into Equivalent Inherent Strain Method}

Poor accuracy solution was achieved in case of the estimation of skin plate distortion caused by fillet weld with reinforcement, e.g. stiffener, longitudinal, transverse frame. The reason of poor accuracy is seen that the acting point of tendon force, which has close relation to the skin plate distortion, has a certain error because of ignoring the weld bead for the finite element modeling.

In this research, following improvement points about finite element modeling are introduced to the former equivalent inherent strain method.

1. Weld bead is idealized by using beam element.

2. Both nodes of weld bead idealized by beam element and skin plate idealized by shell element are shared along weld line.

3. Equivalent inherent strain generating longitudinal shrinkage is inputted in beam element.

4. All of beam elements have bending and torsional rigidity.

Applying above-mentioned modeling to the calculation, improvement of the accuracy of calculation is expected, because the acting points of tendon force in the model approach to the actual condition and the rigidities which weld bead has are considered in the analysis.

\section{CALCULATIONS Calculating Object}

Figure 3 is the structural model imitated a double bottom of hull structure. Out-of-plane displacement of certain points on the skin plate was measured in order to compare with the solutions by improved equivalent inherent strain method. Measuring 

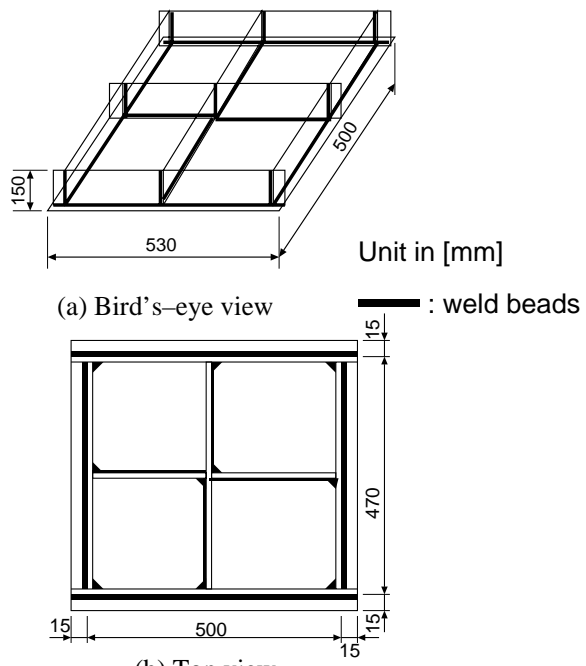

(b) Top view

Figure 3. TEST MODEL CONFIGURATIONS

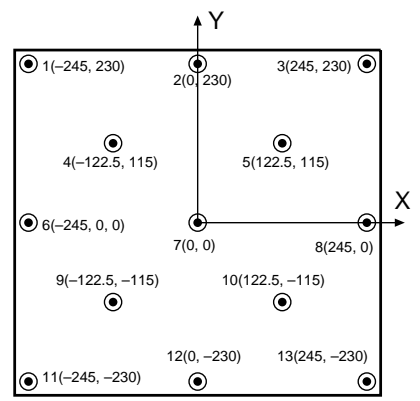

Figure 4. MEASURING POINTS ON SKIN PLATE

Table 1. PLATE ELEMENTS OF THE TEST MODEL

\begin{tabular}{|l|l|}
\hline Part & Dimensions (unit in mm) \\
\hline Skin plate & $530 \times 500 \times 10$ \\
\hline Frame & $530 \times 150 \times 11$ \\
& $470 \times 150 \times 11$ \\
\hline Floor plate & $233.5 \times 150 \times 11$ \\
\hline Girder & $470 \times 150 \times 11$ \\
\hline
\end{tabular}

points on the skin plate are shown in figure 4. Principal dimensions of each plate used to the model are listed in Table 1.

Figure 5 shows the welding sequences applied to the fabrications. Fabrication process can be categorized into five stages. Two fabricating sequences listed below were adopted.

Sequence (I): From outer side welding to inner side

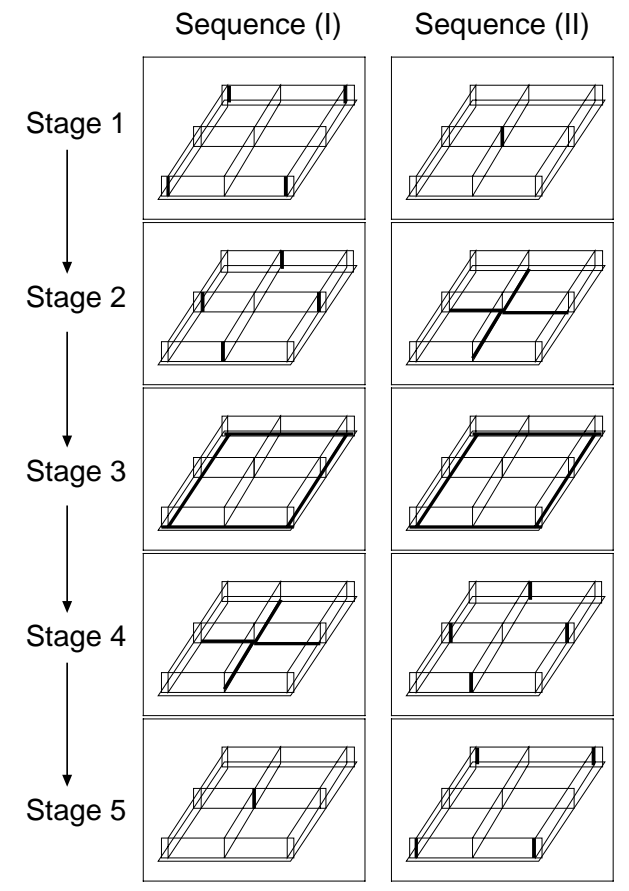

Figure 5. WELDING SEQUENCES AND ANALYSIS STAGES

Table 2. WELDING CONDITIONS

\begin{tabular}{|c|c|c|c|c|}
\hline \multicolumn{5}{|c|}{ Sequence (I) } \\
\hline Stage & $\begin{array}{c}\text { Current } \\
{[\mathrm{A}]}\end{array}$ & $\begin{array}{c}\text { Voltage } \\
{[\mathrm{V}]}\end{array}$ & $\begin{array}{c}\text { Travel speed } \\
{[\mathrm{mm} / \mathrm{s}]}\end{array}$ & $\begin{array}{c}\text { Leg length } \\
{[\mathrm{mm}]}\end{array}$ \\
\hline 1,2 & 230 & 23 & 5 & 6 \\
\hline 3,4 & 230 & 23 & 7 & 5 \\
\hline 5 & 230 & 23 & 5 & 5 \\
\hline \multicolumn{5}{|c|}{ Sequence (II) } \\
\hline 1 & 230 & 23 & 5 & 5 \\
\hline 2,3 & 230 & 23 & 7 & 5 \\
\hline 4,5 & 230 & 23 & 5 & 5 \\
\hline
\end{tabular}

Sequence (II): From inner side welding to outer side

Each welding was performed after passing sufficient long time to dissipate the temperature rise caused by former welding pass. Welding order in each stage was a diagonal and symmetrical.

All of the welding were operated by fillet weld with one pass and its designed leg length is $5.0 \mathrm{~mm}$. $\mathrm{CO}_{2}$ arc welding with flux cored wire, which wire diameter is equal to $1.2 \mathrm{~mm}$, was used. All of the welding conditions measured are listed in Table 2.

Net heat input in order to calculate equivalent inherent 


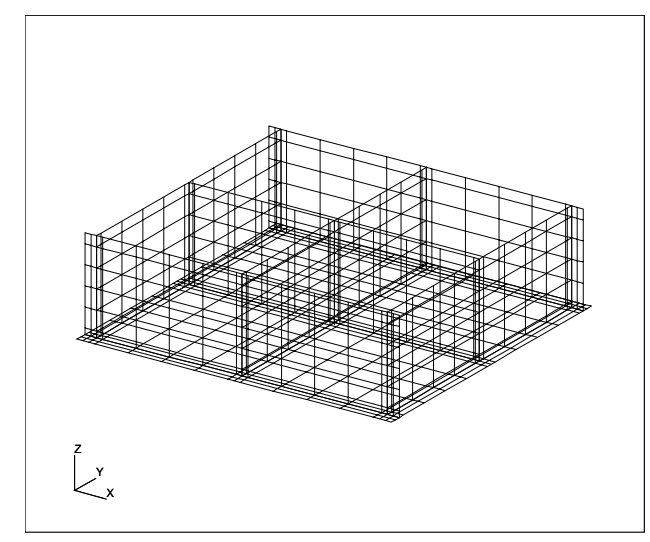

Figure 6. MESH IDEALIZATION OF THE TEST MODEL

strain is estimated by applying the measured welding condition shown in Table 2 and the thermal efficiency of $\mathrm{CO}_{2}$ arc welding, 0.77 (SR237, 2000). Heat input ratio for each plate by fillet weld is estimated by the formula (Cottrell, 1953) in which the ratio of thermal diffusion section in the plate is considered.

\section{Finite Element Modeling}

Detailed information about the finite element modeling is as follows.

1. MSC/NASTRAN (Ver.70.7), which is one of the wide use finite element codes, is applied to the calculations.

2. Equivalent inherent strain in each element neighboring weld line is calculated by equations (1) to (6).

3. Each plate is idealized by four-node shell element (CQUAD4 in NASTRAN). All the element width in the vertical direction are determined to $10 \mathrm{~mm}$, because suitable element width is from $9.1 \mathrm{~mm}$ to $13.0 \mathrm{~mm}$ by equation (7) and Table 2.

4. Each weld bead is expressed by beam element (CBAR in NASTRAN). Cross-section of weld bead is idealized as an isosceles right-angled triangle, which length of two sides forming the right angle is the leg length of fillet weld. Nodal points of the beam element have offset from the node on shell element along the connecting line to the center of gravity of idealized cross section.

5. Each bead element is put in the corresponding stage of the fabrication.

6. Initial configuration in each calculating stage is the calculation result of former fabricating stage, i.e. the effect of welding sequence on this distortion is considered in the calculations.

Mesh idealization of the test model is shown in figure 6.

\section{RESULTS AND DISCUSSIONS}

Both calculation and measurement results of out-of-plane deformation through points $1-2-3,6-7-8$ and $11-12-13$ in the measuring points in figure 4 are compared in order to verify the developed equivalent inherent strain method in here. Final deformations are shown in figures 7, 8, 9 and 10. Measured deformations are shown by solid circle in these figures.

Figures 7 and 8 show the deformation of the each line on $x-y$ and $x-z$ plane by the welding sequence (I). Three different calculating condition are set in order to estimate the deformation. Condition (1) corresponds to consider welding sequence. Finite element model are separated along the connecting line before the welding stage in this calculating condition. Calculation results under this condition are shown by open cricle. In condition (2), welding sequence is ignored. It is supposed that all the welding are performed simultaneously in this condition. Results under this condition are shown by open inverted triangle.

By comparing the results under these two condition with the measured one, condition (2) shows better agreement with the measurement than condition (1). In these calculations, influence of the tack welding, which was performed before stage 1 in each fabrication, are not considered. The constraint along each connecting line under condition (1) is loose comparing with the measuring model. These results indicate that the constrain effect by tack welding is not ignored in order to estimate the deformation.

The effect of initial constraint condition is investigated as follows. In condition (3),the effect of tack welding is considerd. Nodes of the model, which correspond to the tack welding part, are connected. Other nodes along connecting line are free before the welding stage. Results under this condition are shown by open triangle. This condition corresponds to the middle level tightness between conditions (1) and (2). As a natural result, results under condition (3) locate between above the ones by conditions (1) and (2).

By considering these three conditions, it is concluded that the effect of tack welding cannot be ignored in order to increase the accuracy of calculation about welding deformation. However, the maximum difference among these computational results and measuring ones is about $0.2 \mathrm{~mm}$. Considering meauring error, this difference can be allowed. Besides, general tendency of the deformation by computation and measurement can be seen similar.

Moreover, as it is clear from figure 8 , the shape of distortion caused by fillet welding can be estimated by using the modeling technique introducing the beam element in order to idealize fillet weld bead. The distortion cannot express if the fillet weld bead is ignored in the finite element modeling.

Figures 9 and 10 shows the deformation of the each line on $x-y$ and $x-z$ plane by the welding sequence (II), respectively. Each mark indicates the same meaning to figures 7 and 8. Computation by applying condition (2) are not performed in the calculations concerning sequence (II). In sequence (II), the shape of 


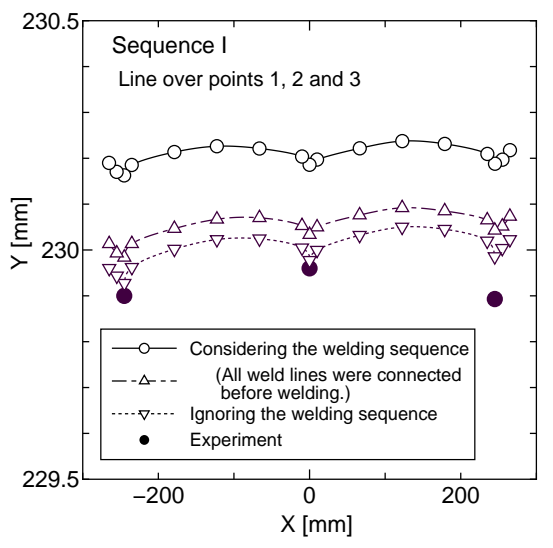

(a) line 1-2-3

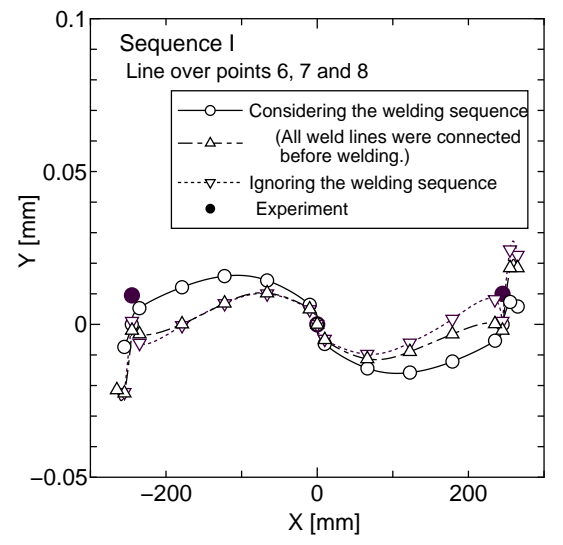

(b) line 6-7-8

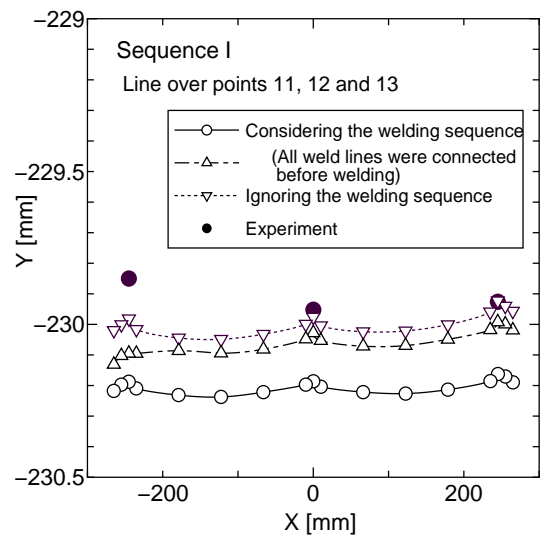

(c) line 11-12-13

Figure 7. DEFORMATION OF THE LINES ON X-Y PLANE (SEQUENCE I)

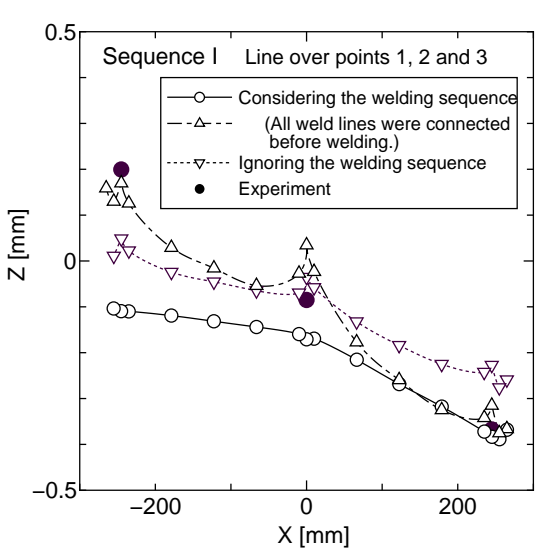

(a) line 1-2-3

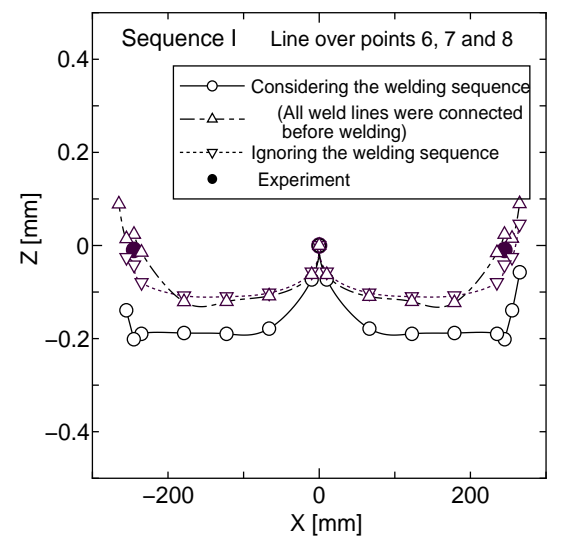

(b) line 6-7-8

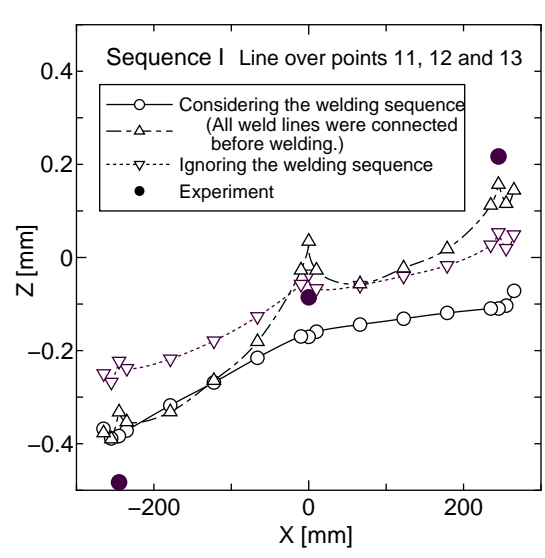

(c) line 11-12-13

Figure 8. DEFORMATION OF THE LINES ON X-Z PLANE (SEQUENCE I)

distortion caused by fillet welding can be also estimated by using the modeling technique proposed.

\section{CONCLUSION}

Equivalent inherent strain method, which is based on the inherent strain as a deformation source and elastic finite element analysis, is improved in order to advance the accuracy of calculation about out-of-plane deformation such as a skin plate distortion caused by fillet weld. Beam element to express fillet weld is incorporated with equivalent inherent strain method. The validity of the improvement suggested here is confirmed by comparing with the measurement result of out-of-plane deformation in the experiment.

Moreover, effect of tack welding is not ignored in order to estimate the deformation by improved equivalent inherent strain method proposed in this article.

\section{ACKNOWLEDGMENT}

The experimental data in this research is a part of the joint research in SR237 Committee of The Shipbuildign Research Association of Japan. Thanks to the committee members to discuss and give useful suggestions about this research.

This research fund was Grant-in-Aid for Scientific Research (B) by Japan Society for the Promotion of Science.

\section{REFERENCES}

Cottrell,C.L.M., Controlled Thermal Sevirity Cracking Test Simulateds Practical Welded Joints, Welding Journal, Vol.32, 1953, pp.257s-272s

Murakawa, H. , Luo, Y. and Ueda,Y., Prediction of Welding Deformation and Residual Stress by Elastic FEM Based on Inherent Strain (First Report) , Journal of The Society of Naval Architects of Japan, 1996 , pp.739-751

Murakawa, H. , Luo, Y. and Ueda,Y., Inherent Strain As an 


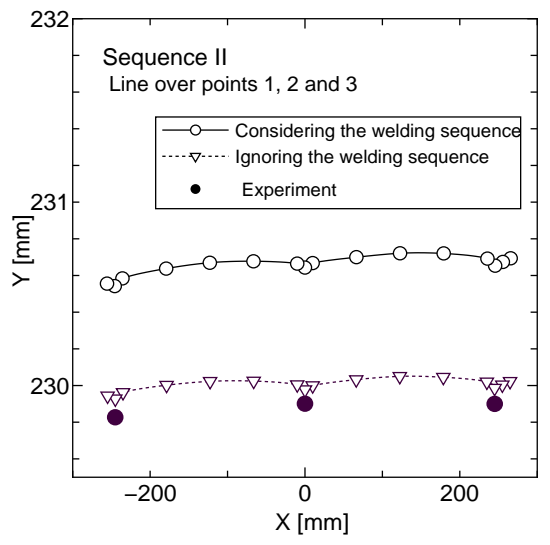

(a) line 1-2-3

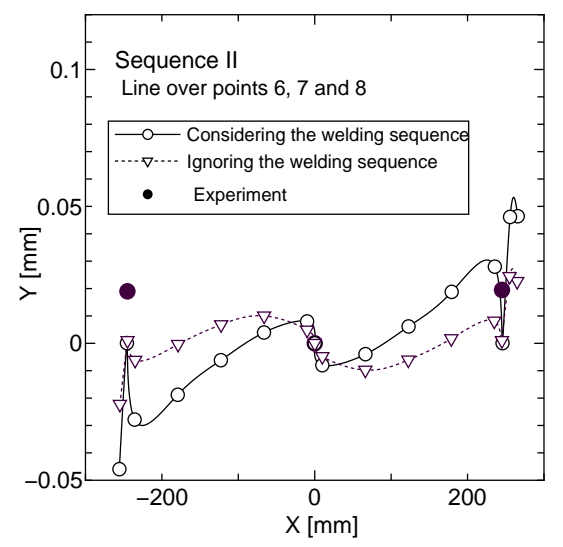

(b) line 6-7-8

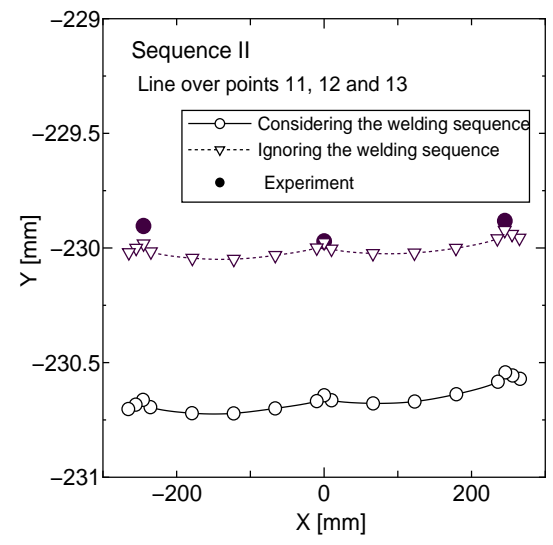

(c) line 11-12-13

Figure 9. DEFORMATION OF THE LINES ON X-Y PLANE (SEQUENCE II)

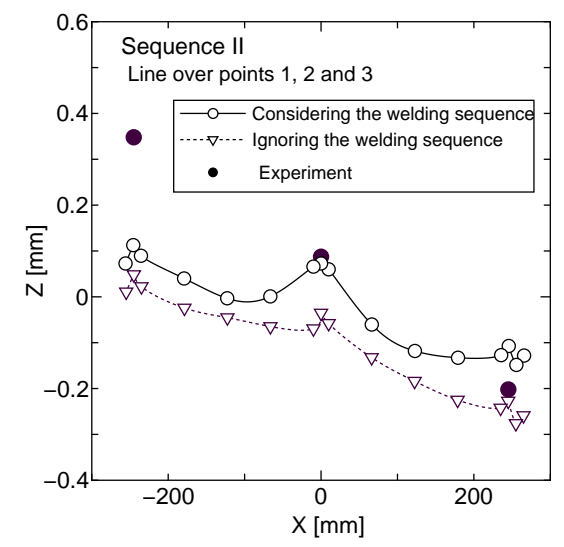

(a) line 1-2-3

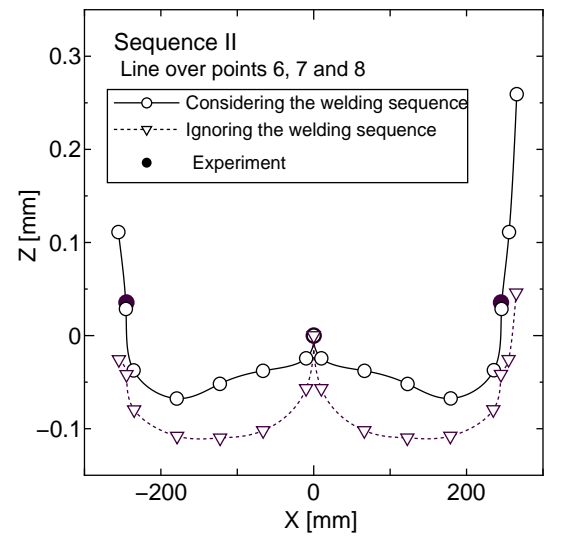

(b) line 6-7-8

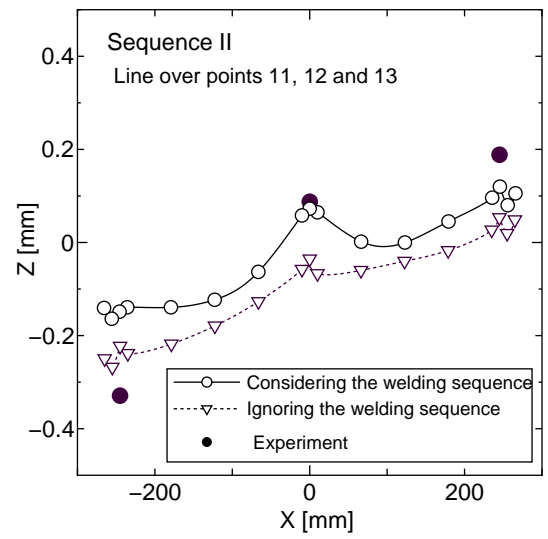

(c) line 11-12-13

Figure 10. DEFORMATION OF THE LINES ON X-Z PLANE (SEQUENCE II)

Interface Between Computational Welding Mechanics And Its Industrial Application, Mathematical Modelling of weld phenomena 4, 1998 , pp.597-619

Satoh, K. and Terasaki, T., Effect of Welding Conditions on Welding Deformations in Welded Structural Materials, Journal of The Japan Welding Society, Vol.45, No.4, 1976, pp.302-308

SR237 Committee, Final Report of SR237 Committee, The Shipbuildign Research Association of Japan, 2000.

White, J.D., Leggatt, R.H. and Dwight, J.B., Weld shrinkage prediction, Welding and Metal Fabrication, November, 1980, pp.587-596 